\title{
Pesquisa-Ação como Resposta Metodológica aos Desafios de Design Social
}

\author{
Action-Research as a Methodological Response to the Challenges of Social Design
}

CAMILLO, Maiara G. D.; Doutoranda em Design; UFSC

maiarag@gmail.com

GUEDES, Irina L.; Mestre em Design; UFSC

irina.lopes@gmail.com

PASQUALOTTO, Felipe P.; Mestre em Design; UFSC

felipepetik@gmail.com

SOUZA, Richard P. L. de; Doutor em Comunicação e Semiótica; UFSC

richard.perassi@uol.com.br

MERINO, Giselle S. A. D.; Doutora em Engenharia de Produção; UFSC

gisellemerino@gmail.com

\section{Resumo}

No contexto das pesquisas técnico-sociais em Design, são evidentes as limitações da tradicional concepção científica para promover a coparticipação comunitária. Através dos questionamentos sobre o papel das atividades de Design na cultura organizacional e comunitária contemporânea, a área foi desafiada a incorporar novos métodos. Esses novos métodos visam a identificação de problemas ou oportunidades de desenvolvimento local, que sejam também compatíveis com a ideia de sustentabilidade econômica e socioambiental. A partir de estudos bibliográficos, são apresentados neste artigo os aspectos socialmente relevantes da Pesquisa-ação. A finalidade é destacar a coparticipação comunitária nos processos de coleta, sistematização e interpretação dos dados da realidade vivenciada e observada. O desenvolvimento da Pesquisa-ação é descrito de acordo com suas particularidades, aplicações e possíveis contribuições aos estudos e à prática em Design, considerando-se duas etapas: a primeira exploratória e a segunda aplicada. Além de serem destacadas as suas correlações com uma atuação social em Design.

Palavras-chave: Design. Metodologia Participativa e Responsabilidade Socioambiental.

\section{Abstract}

In the context of technical-social research in Design, the limitations of the traditional scientific conception to promote community participation are evident. Through the questioning about the role of Design activities in contemporary organizational and community culture, the area was challenged to incorporate new methods. These new methods aim at identifying problems or opportunities for local development that are also compatible with the idea of economic and socioenvironmental sustainability. Based on bibliographical studies, the socially relevant aspects of Action-Research are presented in this article. The purpose is to highlight community participation 
in the processes of collecting, systematizing and interpreting the reality and observed reality data. The development of Action-Research is described according to its particularities, applications and possible contributions to the studies and practice in Design, considering two stages: the first exploratory and the second applied. In addition to highlighting their correlations with a social performance in Design.

Keywords: Design. Participatory Methodology and Social and Environmental Responsibility.

\section{Introdução}

A origem da área de Design foi diretamente atrelada ao projeto de produtos destinados à fabricação mecanizada em escala. Isso ocorreu primeiramente no contexto histórico-cultural da Ciência Positiva e no processo de consolidação da Revolução Industrial. Atualmente, entretanto, a área de Design busca consolidar sua atuação direta na cultura organizacional, na sociedade em geral e, também, em comunidades específicas. Assim, consideram-se as possibilidades de atuar diretamente na dinâmica das organizações e na vida das pessoas, inclusive, desenvolvendo "produtos que respeitem o meio ambiente e o ser humano" (SOBRAL, 2002, p. 49).

Há uma ampla produção teórico-acadêmica sobre as aplicações de Design no contexto industrial, especialmente, incluindo a contínua incorporação de tecnologia para o desenvolvimento de produtos voltados ao consumo de mercado. Contudo, a produção teórica não apresentou o mesmo desenvolvimento no que diz respeito ao papel social de Design (MARGOLIN, 2004). Quando o desenhista industrial Vitor Papanek (1971) apontou os prejuízos sociais decorrentes de sua profissão, muitos foram os profissionais que responderam ao seu chamado e investiram no desenvolvimento de alternativas, visando a sustentabilidade econômica e a responsabilidade socioambiental dos projetos de Design. Mas, isso não resultou necessariamente em metodologias próprias para a solução dos problemas sociais.

Para Perassi, Neves e Cazon (2016), a expressão "Design Social" não designa uma habilitação ou uma especialidade em Design, porque caracteriza uma abordagem sociopolítica que oferece os diversos conhecimentos e os recursos da área aos interesses sociais e comunitários, que também sejam compatíveis com a sustentabilidade econômica e com a responsabilidade socioambiental. Assim, considerar os desafios sociais para a área de Design não requer, necessariamente, a negação dos recursos já existentes quanto às possibilidades tecnológicas desenvolvidas em função da indústria e da fabricação de artefatos. Mas, é necessário que os recursos sejam destinados ao desenvolvimento socioeconômico com responsabilidade socioambiental, porque esses também são valores distintivos de produtos, serviços, atuações e marcas (CAMARGO et al, 2004).

De maneira diferente do desenvolvimento de produtos industriais em escala, a atuação em Design Social, entretanto, requer que os designers estejam envolvidos no contexto comunitário. Anteriormente, isso também foi considerado com relação às organizações sociais, porque a área de Gestão de Design foi prioritariamente desenvolvida para adequar os designers ao convívio empresarial ou institucional. Assim, de maneira integrada às organizações, os designers puderam propor soluções de Design especialmente adequadas ao contexto organizacional. De maneira semelhante, a abordagem de Design Social também requer a interação participava dos designers nas comunidades. 
Para a adequação dos designers ao contexto social comunitário podem ser utilizadas diferentes metodologias, práticas e recursos desenvolvidos em outras áreas do conhecimento como: Sociologia, Antropologia e Gestão. Inclusive, parte disso já foi devidamente adaptada para a atuação em Design Social, considerando-se que, cada vez mais, os designers atuam de maneira comunitária em um contexto cujo significado é único para cada uma das pessoas que o vivencia (FIALHO, 2005).

No processo de interação social comunitária, houve a "ampliação" das atribuições de Design. Portanto, além de seus projetos serem destinados às pessoas, também, tornou-se necessária a interação comunitária dos designers com as pessoas para a identificação de problemas ou oportunidades e o desenvolvimento de projetos adequados às situações específicas. Isso ampliou o campo de interesse e requereu outras abordagens, especialmente no que diz respeito à consideração dos valores e outros fatores humanos em projetos de Design.

A partir disso, não foi possível ignorar a necessidade de observação e interação social em busca de dados empíricos, para serem identificados e representados em conjunto com outros observadores, sendo esses os próprios usuários que devem participar e concordar com a representação que é feita de suas experiências e visão de mundo. Por decorrência, considera-se que os designers autodesignados para atuar em Design Social devem buscar ou desenvolver abordagens metodológicas eficientes para a coleta e a interpretação rigorosa dos dados relacionados ao contexto de desenvolvimento e aplicação de Design (FRAGOSO et al, 2011).

Ander-Egg (1978) assinalou as limitações do sistema de mensuração nos processos de conhecimento empírico. Por sua vez, Lakatos \& Marconi (1993) também apontaram as limitações do conhecimento científico quantitativo. Neste estudo, entretanto, são especialmente consideradas as observações de Vygotsky (1994), sobre a importância da mediação dos instrumentos no aprendizado, evidenciando-se também os aspectos distintivos da abordagem fenomenológica propostos por Husserl (1989). Enfim, enfatiza-se a pesquisa qualitativa, considerando ainda que diferentes abordagens para resolução de problemas requerem estratégias metodológicas igualmente diversas. Portanto, a abordagem de Design Social pode ser amplamente beneficiada com a adoção de métodos qualitativos na fase exploratória, mesmo que seja necessário recorrer à tradição quantitativa para o processo de aplicação. Trata-se, especialmente, de considerar o desenvolvimento da pesquisa-ação no contexto social comunitário.

\section{Pesquisa-ação: particularidades e aplicações}

Tendo sido primeiramente proposta pelo psicólogo alemão-estadunidense Kurt Lewin (1890-1947), a pesquisa-ação é comumente caracterizada como um processo de investigação e ação social comunitária. Isso se justifica pela necessidade de conhecimento e atuação em favor de grupos ou comunidades, os quais necessitam de apoio para o desenvolvimento local, considerando-se aspectos humanos, sociais, culturais, econômicos e financeiros. Em princípio, a interação dos pesquisadores nas comunidades e o caráter sociopolítico e humanitário de sua atuação foram vistos com desconfiança em comparação com o modelo científico, cuja positividade requeria o distanciamento e a isenção do pesquisador com relação ao seu objeto de estudo.

Atualmente, contudo, há diversos estudos já realizados para defender e creditar essa prática de pesquisa. Por exemplo, Thiollent $(1985$, p.17) afirma que a pesquisa-ação valoriza a 
"busca de compreensão e interação entre pesquisadores e membros das situações investigadas", ao invés de investir demasiadamente na quantificação dos resultados empíricos. Para Thiollent (1985), trata-se de um tipo de pesquisa empírica conjugada com ações conjuntas de pesquisadores e participantes da situação problema para encontrarem e aplicarem soluções eficientes na realidade. É a ação decorrente e vinculada ao processo de investigação que caracteriza a pesquisa-ação, sendo que essa deve envolver as pessoas que coletivamente e cotidianamente vivenciam as situações problema ou propiciam as oportunidades que foram identificadas e sobre as quais se pretende atuar de maneira eficiente.

A interação, a coparticipação ou a ação cooperativa dos pesquisadores junto com integrantes das comunidades, visando apenas obter e disseminar conhecimentos, é comumente denominada como "pesquisa participante", não sendo diretamente vinculada a ações práticas e transformadoras da realidade. Portanto, a pesquisa participante busca conhecer a situação vigente, mas não requer necessariamente sua transformação (GIL, 2002). Por sua vez, a pesquisaação aplica o conhecimento na prática, reproduzindo a dinâmica da atuação humana que se propõe a observar, a interpretar e a agir sobre a realidade. Portanto, procura criar, trabalhar e aplicar conhecimentos no processo contínuo de atuação (GIL, 2002). Enfim, a pesquisa-ação é uma pesquisa participante, mas não são todas as pesquisas participantes que podem ser designadas como pesquisa-ação.

Antes da efetiva atuação dos designers, é necessária sua integração e a obtenção de conhecimentos sobre as comunidades. Assim, os designers devem atuar primeiramente como pesquisadores. Por isso, ao tratar da pesquisa-ação, Baldissera (2001) assinala a necessidade de se criar espaços de participação, como parte da metodologia porque, antecipadamente, essa requer oportunidades para que seja efetivada a integração comunitária do pesquisador. Depois de integrado, esse também deve oferecer "às pessoas, os instrumentos e a capacitação necessária para saber como participar" (BALDISSERA, 2001 p. 10), sendo que a participação dos integrantes envolvidos não é uma questão de dever ou direito, mas uma continuidade natural de sua vivência comunitária.

Atualmente a pesquisa-ação é amplamente desenvolvida em diferentes áreas, visando objetivos variados para: Cidadania, Economia, Educação e Saúde, incluindo ações financiadas via Banco Mundial. Para Tripp (2005), na passagem da década de 1940 para 1950, a pesquisa-ação foi adotada em Administração, objetivando o desenvolvimento comunitário ou a mudança organizacional. Mas, também, foi utilizada em Educação. Na década de 1970, a pesquisa-ação assumiu um viés político, visando a mudança sociopolítica, por meio da conscientização e do empoderamento (empowerment) das pessoas integradas em comunidades. Assim, foi também aplicada no desenvolvimento da agricultura brasileira.

Entre outros, Tripp (2005), relaciona à pesquisa-ação autores como: Lewin (1946), Freire (1972; 1982) e Lippitt, Watson e Westley (1958), sendo que todos esses ressaltam os aspectos comunitários, colaborativos e integradores deste tipo de pesquisa. A partir da compreensão de teorias propostas por: Joe (1998), Linda e Karen (1999), Peter e Robinson (1984) e Thiollent (1997), os autores Holanda e Riccio (2001) afirmaram que a pesquisa-ação envolve grupos de estudiosos e profissionais, com o intuito de planejar, agir e avaliar os resultados das ações executadas, monitorando estudos, atividades e resultados.

Tudo isso é representado em uma estrutura espiral (Figura 1), que constitui uma metáfora 
gráfica da recorrência ou da continuidade das atividades, em busca dos resultados esperados. Entre as atividades, é incluído e realizado um "diagnóstico inicial", buscando-se compreender a situação e identificar os problemas que podem ser resolvidos ou as oportunidades a serem aproveitadas. A partir disso, são planejadas as estratégias e as ações práticas, visando-se alcançar os objetivos previstos. Enfim, são também realizadas avaliações parciais, as quais permitem alterações nos rumos dos trabalhos e, por fim, há uma avaliação final, inclusive, considerando-se a possibilidade de revisão de todo o processo e a retomada crítica das atividades, desde o início, para seu aprimoramento em busca de melhorias.

Figura 1 - Estrutura gráfica em espirais como metáfora da pesquisa-ação.

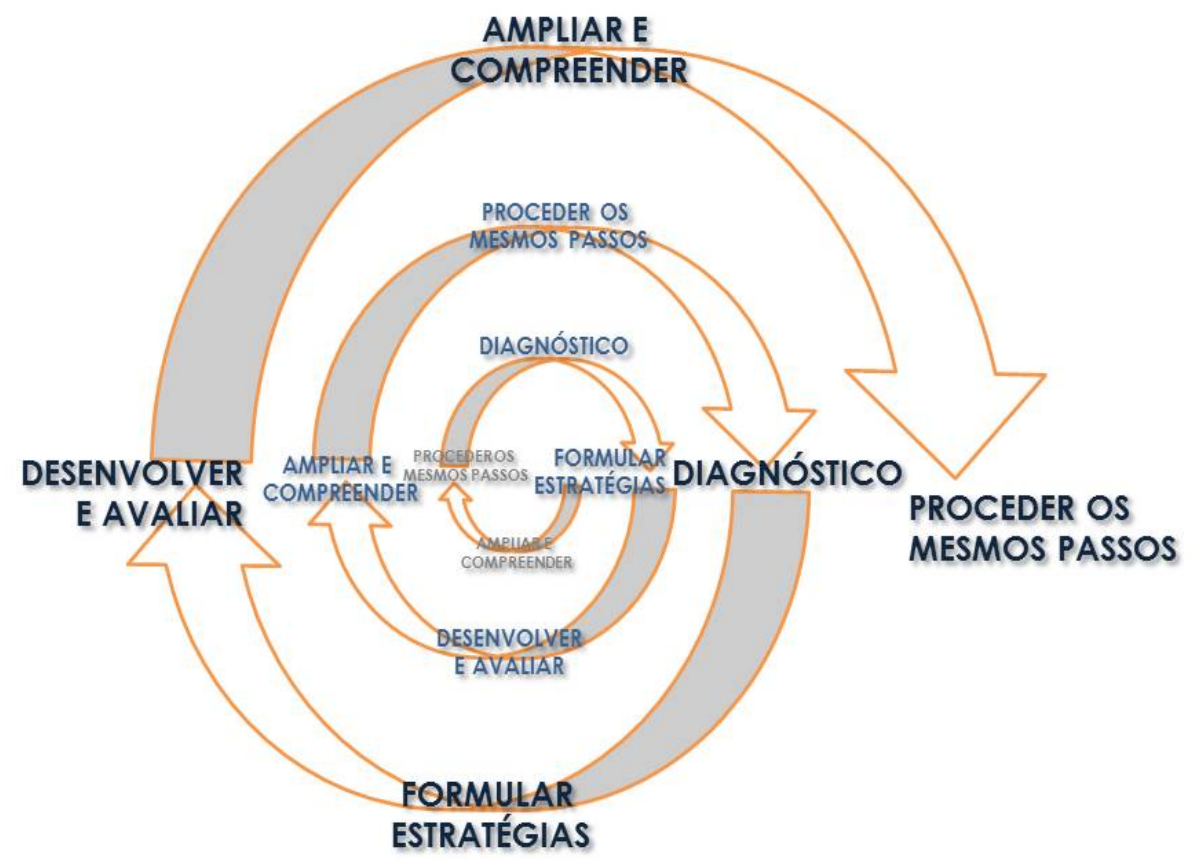

Fonte: Adaptado de Elliot (1997, p.17).

Holanda e Riccio (2001) informam sobre as críticas que recaem sobre certos aspectos da pesquisa-ação, alertando a respeito da recorrente carência de rigor científico. Muitas vezes, também é criticada a falta de efetividade, em decorrência de tentativas de solucionar os problemas de imediato. Mas, pelo em parte, os problemas costumam evoluir, passando por transformações antes que as soluções pesquisadas possam ser implementadas.

Em contrapartida, entretanto, Holanda e Riccio (2001) assinalam as ideias de Dickens e Watkins (1999), como autores que atenuaram as críticas à pesquisa-ação, considerando que essas dependem do juízo que se faz acerca das contribuições esperadas. Assim, consideraram que a pesquisa-ação pode contribuir de diversas maneiras para o conhecimento, diferenciando-se com relação aos outros tipos de pesquisa, especialmente, porque é priorizado o aprendizado através do processo, almejando-se sempre uma melhor compreensão do problema.

Com relação à área de Design, considera-se que a pesquisa-ação oferece recursos de contextualização e coparticipação aos designers, para que esses possam atuar diretamente em grupos sociais ou comunidades. Isso é especialmente requerido na abordagem sociopolítica de Design Social, retirando os designers da tradicional condição de projetistas industriais e indicando-os como agentes sociais, que atuam de maneira integrada nas comunidades. Assim, o desenvolvimento dos 
tradicionais projetos de Design, além de requerer a coparticipação comunitária, também, devem emergir de um metaprojeto de pesquisa-ação.

\section{Design em ações participativas}

Em síntese, a interação entre a atuação em Design e a pesquisa-ação ocorre primeiramente a partir de uma "pesquisa exploratória", para o reconhecimento do contexto e a integração dos designers no grupo ou na comunidade de trabalho. Em seguida, juntamente com os integrantes do grupo ou da comunidade, são realizados os estudos da realidade e a identificação de problemas e oportunidades. Isso caracteriza o metaprojeto social ou comunitário. Em seguida, acontece também a coparticipação coletiva nas etapas de planejamento e projetação das ações de Design, caracterizando as etapas do projeto ou da "pesquisa aplicada".

Para Tenório (1990), deve ser considerado o potencial do conhecimento já adquirido por quem convive cotidianamente na realidade na qual se pretende atuar. Isso justifica a integração consciente dos conhecimentos comunitários nos processos de pesquisa e projetação, porque a busca por soluções eficientes para o enfretamento dos problemas ou aproveitamento das oportunidades não requer apenas os conhecimentos decorrentes do processo formal ou escolar de Educação. Sobre a relação entre os designers e os usuários, Paizan e Mellar (2011) afirmam a necessidade de cooperação para o atendimento das necessidades e o aproveitamento das oportunidades locais. Para isso, é necessário elaborar e adotar práticas específicas, de acordo com o objetivo de cada projeto em particular e, geralmente, essas práticas dependem da atuação participativa.

Sanders e Stappers (2008) assinalam que, na prática atual de Design, há a tendência da comunidade atendida ser considerada parceira, especialmente, nas fases iniciais do projeto, para a definição de requisitos, proposição de ideias e desenvolvimento do conceito. Assim, na abordagem participativa o usuário é parceiro ou participante ativo do projeto. Tal tendência é benéfica por "democratizar" a projetação em coparticipação com os usuários dos produtos ou dos serviços decorrentes de sua interação com os sistemas de produtos projetados. Com isso, busca-se responder de maneira mais fidedigna e eficiente aos interesses ou às aspirações dos usuários, por meio de decisões coletivas e descentralizadas.

Trata-se de investir no conceito de "inteligência coletiva", como foi anteriormente citado por Sanoff (2007). Assim, estimula-se o trabalho em grupo com a somatória de suas perspectivas individuais em busca de resultados coletivos mais significativos. Isso requer a mudança de postura por parte dos envolvidos, que devem renegar o protagonismo individual e investir de maneira colaborativa na emergência da inteligência coletiva, acreditando que isso é mais que a simples soma das perspectivas individuais. Para Sanders e Stappers (2008), essa participação do usuário no desenvolvimento do projeto coletivo é reconhecida como "cocriação", sendo beneficiada pelo compartilhamento criativo entre duas ou mais pessoas. De maneira semelhante, a pesquisa aplicada no desenvolvimento do projeto de Design é denominada de "codesign".

Enfim, os tradicionais papéis destinados aos designers e aos usuários estão sendo revistos sob novos paradigmas. Isso também requer que os designers assumam funções de pesquisadores sociais, atuando diretamente com os grupos ou comunidades de usuários. Por se tratar de projetos e ações de Design, os designers assumem os papéis de coordenadores da pesquisa e orientadores ou facilitadores da atuação coletiva. Mas, ressalta-se que a abordagem sociopolítica em Design Social prevê a pesquisa e o conhecimento de necessidades, preferências, desejos, crenças, origens e valores ideológicos ou éticos dos usuários (STAPPERS; SLEESWIJK VISSER, 2007).

A metodologia de pesquisa-ação, portanto, é aqui apresentada como uma resposta à necessidade de conhecimento da realidade humana e sociológica e ao interesse na coparticipação dos integrantes do 
grupo ou da comunidade estudada. Os objetivos das ações são relacionados às melhorias econômicofinanceiras e socioambientais para toda a coletividade.

A aplicação de estratégias e ações típicas de Design nos processos de gestão de equipes ou da coletividade organizacional já foi anteriormente projetada e testada, caracterizando a prática de Design Thinking (BROWN, 2010). Portanto, essa prática também deve ser considerada como um recurso de Design a ser aplicado no contexto da pesquisa-ação, para desenvolver projetos coletivos e cocriativos. Para Brown (2010), além da sensibilidade dos designers, também, devem ser utilizados os princípios metodológicos de Design para se conhecer as necessidades das pessoas e, ainda, identificar e atender as demandas decorrentes de suas necessidades. Assim, investe-se em inovação centrada no usuário, ou seja, no grupo ou comunidade a ser atendida.

\section{A coparticipação em Design Social}

A característica revolucionária da abordagem sociopolítica de Design Social é expressa na aplicação dos recursos de Ciência e Tecnologia, que são típicos da área de Design. Isso deve acontecer em favor de grupos sociais ou comunidades que não são comumente prestigiados no sistema capitalista. Tradicionalmente, o privilégio recai sobre as relações financeiras de produção e consumo, sendo destinado aos consumidores de alto poder aquisitivo, às indústrias e às empresas em geral. Por sua vez, costumam não ser privilegiadas as ações comunitárias ou implementadas pelo poder público, em áreas como Saúde e Educação, cujo caráter social se destina a atender ao direito coletivo à cidadania.

A abordagem sociopolítica em Design destina os diferentes recursos e ações das diversas habilitações e especialidades da área, para o incremento social das políticas públicas, apoiando também a atuação coparticipante em associações comunitárias, organizações não governamentais (ONGs) e outras iniciativas populares. Assim, consideram-se especialmente os projetos relacionados às melhorias nas ações de Saúde, Educação e outras, que também são relacionadas à plena conquista da cidadania nas comunidades, incluindo iniciativas para geração de trabalho e renda.

Há o especial interesse por ações relacionadas aos conceitos de comunidades criativas, grupos produtivos, capital social, economia solidária, sustentabilidade e responsabilidade socioambiental, entre outros. Isso envolve tudo que pode ser decorrente da própria iniciativa comunitária, mesmo que seja financiado com recursos destinados a projetos, seja pelo acesso a verbas públicas ou em decorrência dos recursos que as empresas destinam ao financiamento de ações socioambientais.

Considerando-se o potencial comunitário para o planejamento e o desenvolvimento de projetos e ações em benefício da coletividade, as estratégias e ações de Design Thinking são também consideradas eficientes no estabelecimento das bases comunitárias colaborativas. Isso é efetivado na mediação dos processos de conhecimento coletivo e aprendizagem, promovendo a consciência do direito coletivo à cidadania e permitindo a troca de saberes entre os integrantes da comunidade. Assim, são favorecidos a participação, a colaboração, o envolvimento e o comprometimento da comunidade, em função de seu próprio processo de transformação social.

É relativamente recente o despertar da consciência pública de que, em virtude de sua humanidade, todos os cidadãos têm o direito universal à cidadania. Os direitos, as responsabilidades e os deveres são atribuídos na participação do indivíduo no grupo familiar e na sociedade, seja como membro de nação, religião, classe social ou comunidade. Diante disso, Design Social qualifica uma abordagem sociopolítica cidadã, buscando entre as potencialidades de sua área do conhecimento solucionar problemas sociais e ambientais, reduzindo desigualdades e enfrentando a violência social e a poluição ambiental, entre outros problemas característicos do constante desordenamento político, econômico, social e cultural (CASTRO et al., 2004).

A adoção da abordagem sociopolítica identificada como Design Social implica em diversas 
mudanças e adequações com relação à tradicional atuação dos designers. Em geral, os projetos de Design Social são relacionados com pequena escala de produção, mercado local, tecnologia adaptada ou adequada à situação comunitária, privilegiando a função prática, o baixo custo e a inclusão social. Tradicionalmente, porém, os projetos de Design Formal são relacionados com a produção em grande escala, visando o mercado global e privilegiando a alta tecnologia, o consumo exagerado, a função estético-simbólica e o preço mais elevado.

Enfim, considera-se que a abordagem sócio-política de Design Social busca desenvolver a coparticipação comunitária. Isso deve ocorrer no planejamento e na realização de ações eficientes de Design que, efetivamente, promovam avanços humanos coletivos, sejam esses econômicos, financeiros, sociais, ambientais ou educativos. Contudo, essas ações são prioritariamente destinadas aos grupos sociais ou às comunidades, locais ou político-culturais, que são prejudicados em sua cidadania, por indigência social, questões raciais, sexuais, culturais ou sociopolíticas.

\section{Discussão e considerações finais}

O que demarca a diferença entre a pesquisa-ação e os outros tipos de pesquisa, incluindo os estudos aplicados técnico-científicos, é a concomitância entre pesquisa, participação e ação comunitária, visando a resolução de problemas coletivos ou o aproveitamento das oportunidades que são identificadas no contexto da coletividade (THIOLLENT, 2008).

As críticas destinadas à pesquisa-ação, geralmente, são baseadas nos pressupostos científicos tradicionais, os quais assinalam a necessidade de distanciamento e isenção dos pesquisadores, com relação aos seus objetos de pesquisa. Sobre isso, há diferentes posicionamentos definindo os procedimentos na etapa exploratória da pesquisa-ação, que ocorre antes da etapa de aplicação das soluções, as quais são comumente desenvolvidas com metodologias próprias de Design. Assim, são diversos os posicionamentos adotados na etapa exploratória:

- Há o posicionamento mais livre, de base Fenomenológica, que é adotado por pesquisadores designers, em observações e ações diretas e interativas, seguindo a filosofia de Edmund Husserl (1859-1938) ou ainda atuando fenomenologicamente, mas de maneira mais metódica e sistemática (MOREIRA, 2004).

- Há também o posicionamento instrumental ou instrumentalista, que se utiliza de um método e instrumentos de pesquisa já validados, como um sistema de controle, com as finalidades de impor distanciamento e garantir certo grau de isenção por parte dos pesquisadores. Assim, os procedimentos e o modo de interpretação dos pesquisadores são previamente designados por esse instrumental de pesquisa.

- Há o posicionamento adotado a partir da tradição metodológica em Antropologia, utilizando-se do método etnográfico. Assim, os pesquisadores designers realizam pesquisas que são desenvolvidas e indicadas como Etnografia (WASSON, 2000).

- Há, ainda, o posicionamento que é privilegiado neste artigo, o qual resulta da adoção e da aplicação metodológica dos recursos de Design Thinking (BROWN, 2010), sendo isso justificado pela integração pré-existente entre a área de Design e a gestão de coletivos de pessoas.

Reforça-se, portanto, a indicação da pesquisa-ação, com recursos de Design Thinking, como processo integrador de teoria e prática, sendo especialmente adequado aos pesquisadores designers interessados na abordagem sociopolítica de Design Social. Isso inclui também ideias ou princípios de Design participativo e co-criação ou colaboração, envolvendo designers e usuários: (1) em benefício do desenvolvimento local de comunidades que ocupam um mesmo lugar geográfico ou (2) visando garantir o 
direito à cidadania para integrantes de comunidades simbólicas, cujos integrantes vivem em lugares do planeta, mas são representantes de minorias sociais em decorrência da situação de indigência social ou por características de, raça, gênero, sexualidade ou posição política, entre outras.

A consolidação da área de Design foi uma primeira decorrência da cultura industrial de bens de consumo que, inclusive, culminou na indústria cultural que atribui valor simbólico aos bens de consumo. Além disso, o progresso do desenho industrial foi também promotor de áreas como Marketing e Publicidade, entre outras. Todavia, a atual crise econômica e socioambiental do capitalismo globalizado necessita de soluções revolucionárias e, também, de soluções pontuais, que melhorem de imediato a vida das pessoas em sua relação com a sociedade e com o ambiente.

Há, portanto, um chamado social para que a área de Design deixe de ser parte exclusiva do problema, passando também a contribuir no desenvolvimento e na implementação das soluções requeridas. Para Manzini (1994), a área de Design pode e deve contribuir no planejamento e na implementação de estilos de vida mais condizentes com a crítica realidade ambiental e com uma sociedade mais justa e igualitária. Enfim, para assumir a responsabilidade socioambiental e atuar na direção proposta, os designers vocacionados também podem e devem assumir a abordagem sociopolítica de Design Social, desenvolvendo projetos co-criativos de pesquisa-ação, especialmente, junto às comunidades e aos grupos sociais que carecem de pleno direito à cidadania.

\section{Referências}

ANDER-EGG, Ezequiel. Introdução às técnicas de investigação social: para trabalhadores sociais. 7. ed. Buenos Aires: Humanitas, 1978.

BALDISSERA, Adelina. Pesquisa-ação: uma metodologia do "conhecer" e do "agir". In: Sociedade em Debate. Pelotas, 7(2):5-25, agosto/2001. Disponível em: <http://revistas.ucpel.tche.br/index.php/rsd/article/viewFile/570/510> Acesso em: 16 jun. 2016.

BROWN, Tim. Design Thinking: uma poderosa metodologia para decretar o fim das velhas ideias. Rio de Janeiro: Elsevier, 2010.

CAMARGO, A.; CAPOBIANCO, J.; OLIVEIRA, J. Meio ambiente Brasil: avanços e obstáculos pós-Rio92. 2 ed. São Paulo: Estação Liberdade; instituto Socioambiental; Rio de Janeiro: Fundação Getúlio Vargas, 2004.

CASTRO, A. et al. Design Social: uma ação e reflexão sobre a prática de ensino e a formação profissional. In: 60 P\&D Design, 2004.

FIALHO, A.; BRAVIANO, G.; SANTOS, N. Métodos e técnicas em Ergonomia. Florianópolis, SC: Editora dos Autores, 2005.

FRAGOSO, S.; RECUERO, R.; AMARAL, A. Métodos de pesquisa para Internet. Porto Alegre: Sulina, 2011.

HUSSERL, E. A ideia de Fenomenologia. Lisboa: Edições 70, 1989.

LAKATOS, E.; MARCONI, M. Fundamentos de Metodologia Científica. São Paulo: Atlas, 1993.

LINDA, D.; KAREN, W. Action research: Rethinking Lewin Management Learning. Thousand Oaks: 1999.

MANZINI, E.; VEZZOLI, C. O desenvolvimento de produtos sustentáveis. São Paulo: EDUSP, 2005. 
MARGOLIN, V.; MARGOLIN, S. Um Modelo Social de Design: questões de prática e pesquisa. In: Revista Design em Foco, vol. I, núm. 1, julho-dezembro, 2004, pp. 43-48 Universidade do Estado da Bahia, Bahia, Brasil.

MOREIRA, D. A. (2004). O Método Fenomenológico na Pesquisa. Thomson Pioneira. Human organization, vol.59, $n^{\circ} 4,2000$.

PAIZAN, D.; MELLAR, H. Envolvendo os alunos no design de tecnologia educacional: aprendendo com o design participativo. Estudos Linguísticos e Literários: saberes e expressões globais, Foz do Iguaçu, 2011.

PAPANEK, Victor. Design For the Real World. New York: Pantheon Books, 1971.

PERASSI, R.; NEVES, L.; CAZON, E. A construção da marca social em Design solidário. Florianópolis, SC: CCE/UFSC, 2016.

SANDERS, E., STAPPERS, P. Co-creation and the new landscapes of Design. CoDesign International Journal of CoCreation in: Design and the Arts, 4(1), 5-18, 2008.

SANOFF, H. Special Issue on participatory Design. In: Design Studies, v.28, n.3, maio 2007.

SOBRAL, S. Tendências do design. In: LEAL, J. Um olhar sobre o design Brasileiro. São Paulo: Objeto Brasil; Instituto Uniemp; Imprensa Oficial do Estado, 2002.

STAPPERS, P.; SLEESWIJK VISSERS, F. (2007). Bringing participatory design techniques to industrial design engineers. Engineering and Product Design Education Conference, NewCastle, 2007, 117-122.

TENORIO, F. O mito da participação. In: Revista de Administração Pública, Rio de Janeiro, v. 24, n. 3, maio/jul., 1990.

THIOLLENT, Michel. Metodologia da Pesquisa-Ação. São Paulo: Cortez,1985.

TRIPP, David. Pesquisa-ação: uma introdução metodológica. Educação e Pesquisa, São Paulo, v. 31, n. 3, p.443-466, 2005. Set/dez. Disponível em: <http://www.scielo.br/pdf/ep/v31n3/a09v31n3.pdf>. Acesso em: 28 jun. 2016.

VYGOTSKY, L. S. A formação social da mente: o desenvolvimento de processos psicológicos superiores. 5a Edição, São Paulo, Martins Fontes, 1994.

WASSON, C. Ethnography in the field of Design. In: Human Organization; Winter 2000; 59, 4; ProQuest. 